\title{
Model and Non-Model Mothers Are Similar Over Significant Aspects of Maternal-Child Health Behaviors in Rural Contexts of Central Ethiopia: Diffusing Healthy Behaviors
}

\author{
Yohannes Kebede ${ }^{1, ~ *, ~ G e m e c h i s ~ E t a n a ~}{ }^{1}$, Eshetu Girma² \\ ${ }^{1}$ Department of Health, Behavior and Society, Faculty of Public Health, Institute of Health, Jimma University, Jimma, Ethiopia \\ ${ }^{2}$ School of Public Health, Addis Ababa University, Addis Ababa, Ethiopia
}

Email address:

yohanneskbd@gmail.com (Y. Kebede)

${ }^{*}$ Corresponding author

To cite this article:

Yohannes Kebede, Gemechis Etana, Eshetu Girma. Model and Non-Model Mothers Are Similar Over Significant Aspects of Maternal-Child Health Behaviors in Rural Contexts of Central Ethiopia: Diffusing Healthy Behaviors. Science Journal of Public Health.

Vol. 7, No. 1, 2019, pp. 10-24. doi: 10.11648/j.sjph.20190701.13

Received: January 17, 2019; Accepted: February 16, 2019; Published: March 11, 2019

\begin{abstract}
Background: Health Extension Program (HEP) was launched-innovative community health service since 2002 in Ethiopia. Since then, families were graduated as models for the HEP. Maternal and child Health (MCH) was one of the major packages in HEP. This study intended to compare model and non-model families (MFs and NMFs) on MCH behaviors. Method: Correlational study was conducted between mothers' model status and MCH service use in Sebeta Hawas district, Oromia special zone surrounding Finfine. A total of 305 samples were involved in the study from both MFs and NMFs. We applied simple random sampling. A pretested and structured questionnaire adopted from literatures together with discussion guides was used. It mainly composed of utilization of Family Planning (FP), antenatal care (ANC), delivery care (DC), postnatal care (PNC) and immunization. Quantitative data was analyzed using Statistical Package for Social Sciences (SPSS) version 16. We used frequency tables to describe model status. Odds Ratio (OR) was used to identify demarcations between MFs and NMFs. Finally, quantitative and qualitative findings was triangulated. Result: The study showed statistically significant key variations between MFs and NMFs over family size, knowledge of (ANC, delivery complications and PNC) and utilization of (FP and ANC visits). These variables were positively linked with being from MFs. For example, 114/201 (56.7\%) current FP users, 120/222 (54.1\%) any ANC visitors, and 56/82 (68.3\%) repeated ( $>=4)$ ANC visitors were from MFs compared to NMFs $(\mathrm{PV}<0.001)$. However, mothers from MFs \& NMFs had no variation on delivery, PNC \& immunization utilization. Closure of health posts at work time, inaccessible institutional delivery service (for MFs) and perceived invulnerability to delivery complications (for NMFs) hampered the MCH behaviors. Conclusion: Though MFs and NMF were similar over some MCH service knowledge and utilization, they vary over FP and ANC. MFs can be advocate for enhancing adoption and diffusion of earlier stage MCH behaviors. However, beyond the control contexts hindered MFs from playing their role of modeling late stages $\mathrm{MCH}$ behaviors (DC/ PNC/immunization). Therefore, HEP designers and implementers shall work on system challenges and create separate models for those behaviors and assign new name.
\end{abstract}

Keywords: HEP, MCH, Mothers, Model Families, Sebeta-Hawas District, Ethiopia

\section{Introduction}

Since Alma-Ata declaration, nearly for the last four decades, primary Health care (PHC) services have become major global health and economic concern [1]. Based on PHC approach, Ethiopia ministry of health $(\mathrm{MOH})$ has formulated four consecutive phases of comprehensive Health
Sector Development Plans (HSDPs) to be implemented within 20 years. The first phase was implemented between 1996/97 and 2001/2. Subsequently, the HSDP II, III and IV consecutively took their next five years of implementation till now. Over these periods, the federal $\mathrm{MOH}$ has formulated and implemented a number of policies and strategies that afforded an effective framework for improving health in the 
country including the recent addition of maternal and neonatal health. One of the focused strategies under implementation starting from the HSDP II has been the training and deployment of new health workforce at grass root levels-the female Health Extension workers (HEWs) who provide health services at village settings [2-6].

The Health Extension Program (HEP) is an innovative health service delivery approach with defined package health services targeting households (HHs) through Primary Health Care Unit (PHCU) platform that comprises of one health center with 5 satellite health posts within the radius of 10 KMs [4-5]. It was first launched in 2002/3 in five regions of the country. It was designed to improve the health status of families by providing healthy living knowledge and skills that empower the HHs to take responsibility that lead them to healthy life styles. Accordingly, each village (locally named as ganda) will have one health post serving 16 HEP packages under 4 thematic areas. Theme 1: Disease Prevention and Control (Prevention and control of HIV/AIDS \& other sexually transmitted infections (STIs), TB and Malaria and First Aid emergency measures). Theme 2: Family Health (MCH-Maternal and child health, Family planning, Immunization, Nutrition, Adolescent reproductive health). Theme3: Hygiene \& Environmental Sanitation (Excreta disposal, Solid \& liquid waste disposal, Water supply and safety measures, Food hygiene and safety measures, Healthy home environment, Control of insects \& rodents, Personal hygiene) and Theme 4: Health Education and Communication (cross cutting)[6]. The program packages have been rendered by the HEWs, through outreach (like home visits) and in-the-health post activities. Creating model families (MFs) for HEP packages has been one of the strategies to enhance adoption of the HEP packages into the social system and healthy behaviors [4-6].

This study focused on $\mathrm{MCH}$ (ANC, PNC, delivery services, FP and immunization) services utilization, of the HEP packages [6]. It was well noted that $\mathrm{MCH}$ packages had direct effect in achieving global goals by reducing maternal and child Mortality. One of the targets of the sustainable Development Goals (SDGs) has been to reduce the underfive mortality rate by two-thirds within 1990-2015 [7-12]. In fact, under-five mortality was declined by $47 \%$ (166 to 88 deaths per 1,000 live births) over the last decade in Ethiopia (2000-2011, EDHS). So do maternal mortality reduced by $72 \%$ [13-16]. Now, the HEP can be taken as the main vehicle for bringing key maternal, neonatal and child health interventions into effect in Ethiopian community, especially in rural contexts. Additionally, evidences indicate $\mathrm{MCH}$ services use has been a critical challenge in numerous African countries, needing improvement for achievement of the SDGs [26-31]. Many studies conducted in various settings in Ethiopia showed MCH aspects: family planning, antenatal care, delivery care, post-natal care, and immunization were low and needed improvement expectedly through the new program, the HEP strategies [17-25].

One of the approach in HEP is identification and training of model families that have acceptance and credibility by the community, as early adopters of desirable health practices to become role models in line with the packages. Model families help to diffuse health messages leading to the adoption of the desired practices and behaviors by the community. In fact, one of the strategies for improved health behavior at individual, family and community level is working on selected units of individuals, families or community, empowering them and using them as advocate. Once these targets fulfill some features for effective models, they can be utilized for expansion of healthy living knowledge, principles and actions. However, the modalities through which these models were produced/selected, named and used in HEP strategies, determine the level of effectiveness on production of healthy behaviors among targeted groups or community [32].

According to the HEP, some families who received some forms of education and brought some improvement at household $(\mathrm{HH})$ levels: kept sanitation, hygiene, properly disposed wastes, built toilets and the like becomes graduated as models families [6]. Formally speaking, model families were those households who received certificate from district health office that declared them as model family. And, nonmodel families were those households living in the same setting who didn't receive any certificate that claimed so. Once the families were declared model, the HEWs use them as models for the rest of the HEP packages. In fact, the mechanisms for selection of the model families looked inconsistent sometimes when checked against observable changes in the HHs. Plus; these models were not produced at least for each HEP theme separately. It seems some of them were getting the names that they did not deserve.

Therefore, the researchers question if families named as model really exhibit variations in $\mathrm{MCH}$ service knowledge and use. And, to look if they can at least act as early adopters by providing some features of models for the rest of the women in their surroundings. Therefore, it is timely and appropriate to compare $\mathrm{MCH}$ services knowledge and utilization between mothers from model and non-model families in Sebeta Hawas district Oromia special zone surrounding Finfine and suggest strategies to go for effective health behavior expansion in community for family health theme and beyond.

\section{Method}

\subsection{The Study Design and Setting}

Comparative cross-sectional study was employed mixed with qualitative methods to compare model families and nonmodel families against maternal and child health services in Sebeta Hawas district. In this study, model families were those households who received certificate from district health office that declared them as model family. And, non-model families were those households living in the same setting who didn't receive any certificate that claimed so. Sebeta Hawas is one of the 5 districts in the Oromia special zone surrounding Finfine. It comprises of 40 gandas (villages); 3 
urban and 37 rural. In the district, there were about 24,074 households with total population of 132,294 (66,133 men and 64,161 women) based on 2007 estimation. About $94.44 \%$ of the population resides in rural parts of the district. The district is bounded by South west Showa in the south and West, Walmera and Addis Ababa in the North and Akaki district in the East [33]. A total of 6 health centers and 40 satellite health posts surrounding the health centers (one for every ganda/village) were present in the district providing primary health care services at grass root level. Regarding health man power there were 74 HEWs and 82 higher health professionals including nurses, health officers and few general practitioners. We conducted this study in seven selected rural villages of the district between November 20 and December 5, 2015.

\subsection{Population}

For this study, mothers from model and non-model households located in a randomly selected seven (out of 37) rural villages of Sebeta Hawas district were considered. Woman in a reproductive age range (15-49 years), who lived in the locality for at least six months and has at least one exposure for delivery (giving birth) in the last five years were included. History of delivery that has been within the last five years was considered because the concept of model families was introduced into the community even few years after launch of health extension program in 2002/3. Women from rural settings were approached because the HEP was initially designed for rural areas and the urban programs had been introduced only recently. In addition, modeling has been perceived as best way of diffusion of $\mathrm{MCH}$ behaviors in rural setting where interpersonal communication is accessible sources of influence.

\subsection{Sample Size}

We calculated the sample size using EpI-info applying two population proportions formula: $\left[\mathrm{n}=\left[\mathrm{Z}_{\alpha / 2}+\mathrm{Z}_{\beta}\right]^{2} *\left[\mathrm{P}_{1}(1-\right.\right.$ $\left.\left.\mathrm{P}_{1}\right)+\mathrm{P}_{2}\left(1-\mathrm{P}_{2}\right) /\left(\mathrm{P}_{1}-\mathrm{P}_{2}\right)^{2}\right]$. We considered the following assumptions: proportion of non-model families who use ANC in rural Ethiopia $\left(\mathrm{P}_{1}=0.34\right.$ [Ethiopian DHS, 2011)(We assumed the ANC figure as reported by EDHS-2011 for rural areas represent non-model families, ANC yielded higher sample size compared to other maternal health indicators), proportion of model families who use ANC was unknown and assumed to be $\left(\mathrm{P}_{2}=50 \%\right)$, level of significance $(\alpha=5 \%)$, standard reliability coefficient at $95 \%$ confidence level (Z 1$\alpha / 2=1.96$ ), the $80 \%$ power to detect significant difference when it happens $(Z \beta=0.84)$ and one to one ratio for MFs and NMFs. Finally considering $10 \%$ non-response rate the calculation yielded to a total of 322 sample size (each of 161 for MFs and NMFs). For the qualitative part of the study, four focused group discussions (FGDs) were conducted with mothers (two FGDs each for MFs and NMFs). In each FGD, 6-10participantswere participated. A total of 34 mothers were involved in all the FGDs. Additionally, we conducted four key informant interview (KIIs) with 1 health office head, 1
$\mathrm{MCH}$ head, $1 \mathrm{HEWs}$ supervisor at district level and 1 HEWs at village level.

\subsection{Sampling Techniques}

First, 7 of the rural gandas found in the district were randomly selected. Based on the finding from one published work on HEP in rural areas [25], about $22 \%$ of the households (HHs) across the rural gandas were expected to be model families. Accordingly, equal proportion of samples to each of the 7 gandas were allocated i.e. a total of $46 \mathrm{HHs}$ (with equal proportion for MFs and NMFs per ganda). Then, equal samples to each of the three lowest area administrative structures (interchangeably named as got or zoni) were further allocated functioning under gandas i.e. 8, 8, $7 \mathrm{HHs}$ keeping proportions for MFs and NMFs across the gares. In order to facilitate random selection, separate sampling frame for MFs and NMFs was first established altogether with their specific ganda and got locations through the assistance of the HEWs. Then, computer generated simple random sampling was applied to select the sample units using the sampling frames. Then, mothers who fulfilled the inclusion criteria were involved in the study. One more visit was tolerated for those closed houses that were randomly selected, otherwise treated as non-response. For qualitative approach the 4 KIIs were selected because they were strategically positioned experts to provide adequate responses about mothers, including their model-status and possible variations against $\mathrm{MCH}$ services. The FGDs were recruited from four gandas relatively distantly located from health centers near to the study setting, where more mothers from model families deliver compared to non-model ones. Here, place of delivery was assumed as best comparator that demarcate between mothers of model families from the non-model ones, as delivery service was not given at health post levels. Purposive (criteria sampling) was used to select mothers whose age range was between 18-49 years (younger and older), who showed variation in number of children they have (limited and many) and from different gares under gandas to participate in the FGDs.

\subsection{Instrument and Measurement}

The instrument was developed for this study through thorough review of documents and guidelines $(6,13-14)$ and related literatures that are specific to $\mathrm{MCH}$ behaviors (1725). The questionnaire has three main parts: part 1) model status, part2) background characteristics (age, marital status, religion, number of children etc.), part 2) utilization knowledge/perception and practice for $\mathrm{MCH}$ services with five sub-sections: family planning, antenatal care, delivery, post-natal care and child immunization. Most of the questions elicited categorical responses on 'yes' or 'no' formats or more close ended options. The questionnaire was pretested among 16 mothers in two other villages in the same district. Then, we improved the appropriateness of the instrument to the level it was believed to be user and consumer friendly. The questionnaire was translated from 
English into Afan Oromo local language and back translated into English to keep the instrument internally consistent. The Afan Oromo version was used for data collection. Complimentarily, qualitative interview guides were used to engage our interviewees and discussants for prolonged time between 30 and 60 minutes. For KIIs, three main concepts were used: 1) overall weakness and strength for health extension program, 2) $\mathrm{MCH}$ services utilization status, reasons, challenges in general and 3) demarcation between model and non-model families in particular concerning $\mathrm{MCH}$ behaviors. Furthermore, for the FGDs we used guides that elicited discussion among mothers based on three main $\mathrm{MCH}$ related dimensions: 1) perceptions and knowledge, 2) experiences, reasons and utilization, and 3) forms and ranges of challenges and expected solutions.

\subsection{Outcome Variables}

$\mathrm{MCH}$ service utilization by mothers was considered as outcome variable of interest to see variations between MFs and NMFs. These include use of FP, ANC, DC, PNC and child immunization. More mothers from MFs were expected exhibit $\mathrm{MCH}$ behaviors than mothers from NMFs. No variation means MFs cannot help to diffuse $\mathrm{MCH}$ behaviors that have been promoted by the HEP through model HHs production strategies. And, more importantly suggest devise new approach for formation of the models.

\subsection{Data Collection Procedures}

The data were collected by three trained diploma holder nurses. The randomly selected houses were traced by the assistance of the HEWs as local guiders. Three trained bachelor degree holder health professionals supervised the data collection. Potential challenges during data collection period was discussed on during training. The data were cleaned every day before submission to immediate supervisors. The investigators conducted the KIIs and FGDs by themselves.

\subsection{Statistical Analysis}

SPSS version 16 software was used for data analysis. Data cleaning and editing was carried out regularly through the course of the survey and after data entry. Missing data were excluded during analysis. Mothers who mentioned more than half of the HEP services were considered as knowledgeable about HEP. Mothers who were using any FP methods were taken as FP users. Mothers who visited HF at least once during last pregnancy were treated as ANC users. In fact, a minimum of four visits were also used for further analysis. Mothers who gave their last delivery at health institutions within the last five years were considered utilized skilled delivery services. Mothers who visited HF for checkup within 6 weeks after delivery were PNC users. And, mothers who immunized their last child were immunization users. Mothers who claimed knowing and using FP, ANC, PNC, and skilled delivery places and immunization were asked for details to display possible further variations. Frequency tables and percentages were used to describe $\mathrm{MCH}$ services use both for MFs and NMFs. Binary logistic regression analysis was executed to compare mothers based on model status. Variables with zero values in any of the comparison cells were excluded during logistic regression analysis. NMFs were consistently reference of interpretation compared to the MFs. We used adjusted Odds Ratio (OR) with 95\% confidence interval $(\mathrm{CI})$, and P-values $(<5 \%)$ to declare predictors of model status (MFs or NMFs) in the contexts of socio-demographic features, $\mathrm{MCH}$ related knowledge and utilization. Thematically analyzed findings from qualitative data were mixed to support the quantitative findings.

\subsection{Ethical Considerations}

The approval for this study was secured from Jimma University Public health and medical science ethical review committee. Then, Zonal health office was communicated through the support letter received from the ethical review committee. Finally, further support letter were obtained from zone to Sebeta Hawas district. The participants were adequately informed about the purpose of, potential risk and benefits, and right to withdraw from the study. Absence of direct risks and benefits was mentioned for participants because of their involvement in the study. In fact, we informed them that their responses are very important to inform the HEP strategies. The participants declared they understood information sheet read out for them before giving their consent. The involvement in the study was entirely based on oral informed consent. Privacy was kept during the study. The responses were kept confidential, as we did not use personal identifiers anywhere in the report.

\section{Result}

\subsection{Socio-Demographic Characteristics of the Respondents}

From a total of 322 households approached, 305 (146 MFs and 159 NMFs) were participated in the study, producing a response rate of $94.7 \%$. In fact, the response rates for MFs and NMFs were $90.9 \%$ and $98.8 \%$ respectively. Table 1 presents the details of the background for respondents. Accordingly, 108 (35.4\%) of respondents were within 25-29 years age ranges. The respondents were predominantly, 264(86.6\%), Orthodox Christianity followers. More than half, 168(55.1\%), of the respondents were not attended formal education. In fact, nearly one-in-three attended the first primary education cycle (1-4 graders). The Oromo ethnic group contributed to $262(85.9 \%)$ of the respondents. With regard to marital status, $283(92.8 \%)$ of them were married. More than two-fifth, $133(43.6 \%)$ of respondents had more than four live births. In fact, slightly lower number, $125(41 \%)$ of children were alive at the time of the study. It seems slight variations were present between mothers from model and non-models based on religion and number of children they had (those who have 4-6 children tend to be models) $(\mathrm{pv}<0.05)$. 
Table 1. Background characteristics of respondents, Sebeta Hawas district, OSZSF, December 2015 (N=305).

\begin{tabular}{|c|c|c|c|c|}
\hline \multirow{3}{*}{$\begin{array}{l}\text { Background Characteristics by } \\
\text { model status }\end{array}$} & \multicolumn{2}{|l|}{ Types of HH } & \multirow{2}{*}{ Total No (\%) } & \multirow{3}{*}{$X^{2}$ (P-value) } \\
\hline & MFs No (\%) & NMFs No (\%) & & \\
\hline & $146(47.2)$ & $159(52.8)$ & $305(100)$ & \\
\hline \multicolumn{5}{|l|}{ Age } \\
\hline $15-19$ & $8(42.1)$ & $11(57.9)$ & $19(6.2)$ & \multirow{5}{*}{$22.5(0.15)$} \\
\hline $20-24$ & $28(38.9)$ & $44(61.1)$ & $72(23.6)$ & \\
\hline $25-29$ & $62(57.4)$ & $46(42.6)$ & $108(35.4)$ & \\
\hline $30-34$ & $28(45.9)$ & $33(54.1)$ & $61(20)$ & \\
\hline 35 and above & $20(44.4)$ & $25(55.6)$ & $45(14.8)$ & \\
\hline \multicolumn{5}{|l|}{ Religion } \\
\hline Orthodox & $118(44.7)$ & $146(55.3)$ & $264(86.6)$ & \multirow{4}{*}{$42.4(0.02)^{* * *}$} \\
\hline Muslim & $9(69.2)$ & $4(30.8)$ & $13(4.3)$ & \\
\hline Catholic & $4(100)$ & 0 & $4(1.3)$ & \\
\hline Protestant & $15(62.5)$ & $9(37.5)$ & $24(7.9)$ & \\
\hline \multicolumn{5}{|l|}{ Marital status } \\
\hline Married & $108(38.2)$ & $175(61.8)$ & $283(92.8)$ & \multirow[t]{2}{*}{$29.3(0.11)$} \\
\hline Others** & $6(27.3)$ & $16(72.7)$ & $22(7.2)$ & \\
\hline \multicolumn{5}{|l|}{ Ethnic group } \\
\hline Oromo & $102(38.9)$ & $160(61.1)$ & $262(85.9)$ & \multirow{3}{*}{$38.5(0.17)$} \\
\hline Amhara & $9(39.9)$ & $14(60.1)$ & $23(7.4)$ & \\
\hline Others* & $8(40)$ & $12(60)$ & $20(7.7)$ & \\
\hline \multicolumn{5}{|l|}{ Educational status } \\
\hline No formal education & $83(49.4)$ & $85(50.6)$ & $168(55.1)$ & \multirow{4}{*}{$47.2(0.66)$} \\
\hline First cycle grade 1-4 & $42(43.3)$ & $55(56.7)$ & $97(31.8)$ & \\
\hline Second cycle grade $5-8$ & $17(54.8)$ & $14(45.2)$ & $31(10.2)$ & \\
\hline High school grade 9-12 & $4(44.4)$ & $5(3.1)$ & $9(3)$ & \\
\hline \multicolumn{5}{|l|}{ Number of alive birth } \\
\hline $1-3$ & $74(43)$ & $98(57)$ & $172(56.4)$ & \multirow{3}{*}{$57.1(0.05)^{* * *}$} \\
\hline $4-6$ & $62(59.6)$ & $42(41.4)$ & $104(34.1)$ & \\
\hline $7-9$ & $14(48.3)$ & $15(51.7)$ & $29(9.5)$ & \\
\hline \multicolumn{5}{|l|}{ Number of alive children } \\
\hline $1-3$ & $72(43.3)$ & $102(56.7)$ & $180(59.0)$ & \multirow{3}{*}{$51.4(0.01)^{* * *}$} \\
\hline $4-6$ & $58(56.9)$ & $44(43.1)$ & $102(33.4)$ & \\
\hline $7-9$ & $8(34.8)$ & $15(65.2)$ & $23(7.6)$ & \\
\hline
\end{tabular}

*Gurage, Tigre and Silte, ${ }^{* *}$ widowed, divorced, ${ }^{* * *}$ statistically significant, $* * * *$ reference group, Abbreviations: HH: Household, OSZSF: Oromia special zone surrounding Finfine.

\subsection{Mothers' Knowledge About HEP and MCH Services and Model Status}

This study assessed distribution of knowledge or awareness related HEP, HEWs and $\mathrm{MCH}$ services among respondents aimed to see variations in proportion based on model status. Table 2 conveys the details. About four in five mothers claimed to be oriented about the activities of the HEWs as community HEP workers. 137/245 (55.9\%) of them were model families (pv<0.001). 237 out $245(96.7 \%)$ mothers who claimed knowing the roles of HEWs, could mention $<6$ activities in connection with HEWs' role from the following lists: nutrition, family planning, antenatal care, immunization, institutional delivery, breast feeding, latrine use, housing condition (how to keep house clean), personal hygiene, environmental sanitation, HIV/AIDs, Tuberculosis and Malaria). Though $296(97 \%)$ of mothers mentioned at least one FP methods, only $221(72.5 \%)$ confidently declared they about FP. 122/221 (55.2\%) were from model families ( $p v=0.12)$. Overwhelmingly, $300(98.4 \%)$ were claimed to be aware of ANC services. In fact, 139/300 (46.3\%) mentioned ANC package involves other services like immunization for healthy pregnancy not just checkup. 76/139 (54.7\%) were model families (pv <0.05). Predominantly, 286 (94.4\%) mothers perceived skilled birth attendances as beneficial. $11 / 17(64.7 \%)$ who perceived institutional delivery as not beneficial were from non-model families $(\mathrm{pv}=0.3)$. Minority, $36 / 222(16.7 \%)$, of the respondents who ever visited health post for ANC reported they were informed about pregnancydelivery complications. However, greater proportion $(28=77.8 \%)$ of those informed were MFs $(\mathrm{pv}<0.001)$. The FGDs also showed that mothers from both groups had no objection about the benefit of delivering at HF but conceived invulnerability to complication; they perceived it as rare occasion. For example, one woman from NMFs who delivered her five children at home said, "it is good to deliver at HF. No objection for that. Women could be best supported at HF if complication is present. But, I delivered all my children at home without encountering any problem. Saint Merry made easy my labor easy". Another woman from MFs said, ".....I have attended ANC services both with HEWs at health post and nurses at health center. Though, they told me to deliver at health institution, I delivered my baby at home with support of traditional birth attendant without complication, difficulty and soon". And, 303 (99.3\%) respondents were aware of child immunization services in HEP. On the contrary, mothers who did not know about the 
need to visit $\mathrm{HF}$ (starting from day 1 through 6 weeks) after delivery takes on the major share, 276(90.8\%).21/28 (75\%) of mothers who were aware of PNC were from model families ( $\mathrm{pv}<0.002)$. Pertaining to source of information about MCH services, majority of the respondents, 186 $(62.0 \%)$ heard from the HEWs. But, greater proportion of those mothers who claimed hearing from other health professionals and media were significantly from NMFs $(\mathrm{Pv}<0.001)$. Overall, report of knowing activities of HEWs as community worker for HEP, knowledge of ANC packages, awareness about PNC and source of information showed significant variation in proportions between mothers from MFs and NMFs (pv<0.005).

Table 2. Awareness and Knowledge about HEP and MCH services, Sebeta Hawas district, OSZSF, December 2015 (N=305).

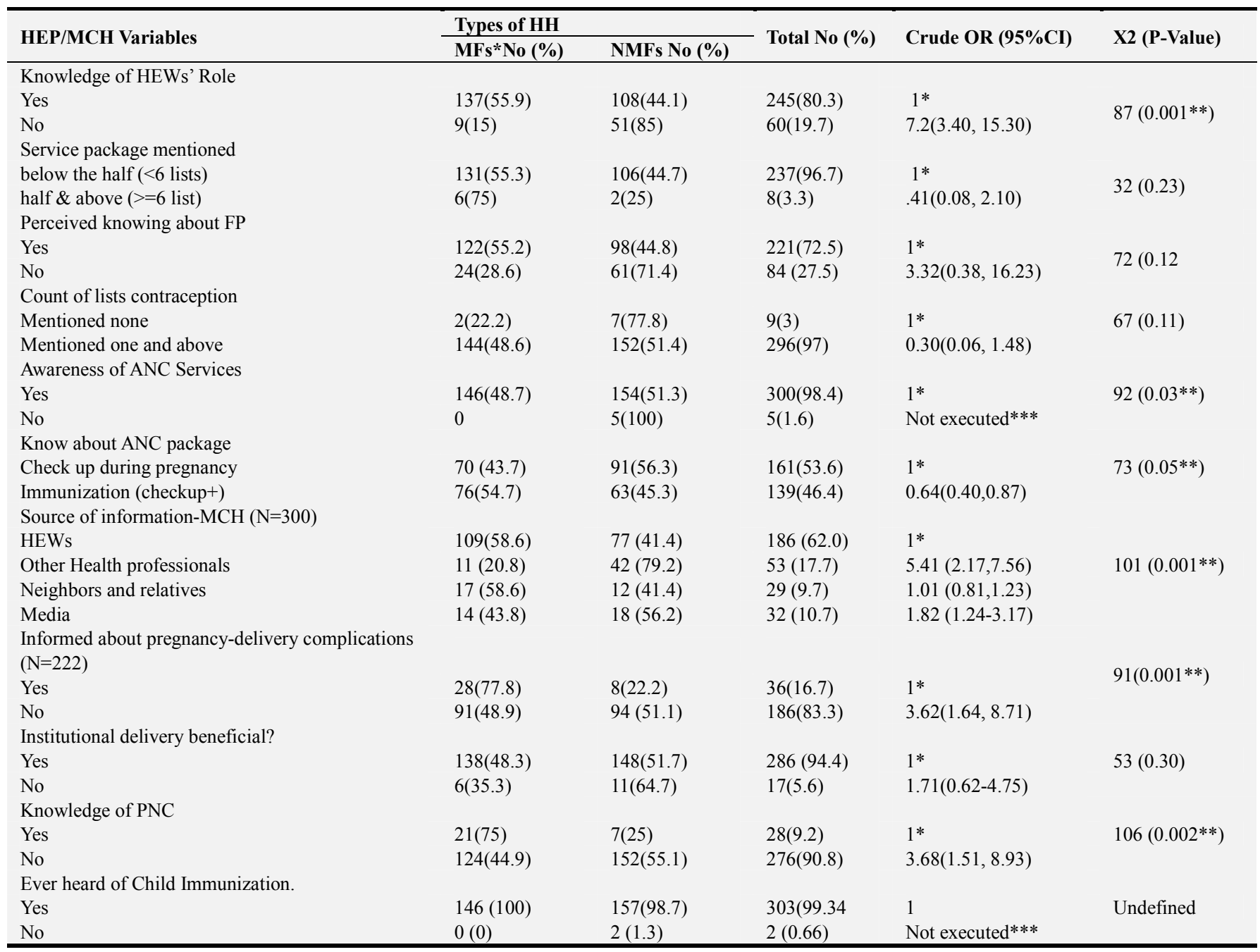

*Reference group, ** statistically significant, ***not executed (zero cells produce undefined odds), Abbreviations: HH: Household, OSZSF: Oromia special zone surrounding Finfine.

\subsection{Mothers' MCH Service Utilization and Model Status}

Table 3 displayed distribution of mothers' use of FP, ANC, DC, PNC and Immunization among model and non-model families. $201(65.9 \%)$ of the respondents were using FP. $114 / 201(56.7 \%)$ were model families ( $\mathrm{pv}<0.001)$. Majority of, 164/201 (81.6\%), the respondents used injectable contraceptive. Though MFs seems to use pills and IUD (intrauterine device) more than NMFs, percentage variation was not significant ( $\mathrm{pv}=0.83) .222(73 \%)$ of the respondents used ANC during their last pregnancy. 120/222 (54.1\%) of them were model families $(\mathrm{pv}<0.001) .82 / 222(36.9 \%)$ of the
ANC users visited $\mathrm{HF}$ at least four times, of whom 56 $(68.3 \%)$ were model families ( $\mathrm{pv}<0.001)$. Overwhelmingly, $233(76 \%)$, the respondents were delivered their last deliveries they made within the past five years. Slightly higher, $37 / 72(51.4 \%)$ of the deliveries made at HF were among model families $(p v=0.29)$. Seventy $(23 \%)$ of the respondents were used PNC services at $\mathrm{HF}$, of them 38 $(54.3 \%)$ were model families ( $\mathrm{pv}=0.14)$. And, $287(94.1 \%)$ used child vaccination service. Higher proportion, 13/18 $(72.2 \%)$ of mothers who did not immunize their children were from non-model families, though slightly insignificantly $(\mathrm{pv}=0.06)$. 
Table 3. Maternal and child health services utilization, Sebeta Hawas, OSZSF, Ethiopia, December 2015 (No=305).

\begin{tabular}{|c|c|c|c|c|c|}
\hline \multirow{2}{*}{ MCH service utilization } & \multicolumn{2}{|c|}{ Types of HH } & \multirow{2}{*}{ Total Freq. (\%) } & \multirow{2}{*}{$\begin{array}{l}\text { Crude } \\
\text { OR(95\%CI) } \\
\end{array}$} & \multirow{2}{*}{ P-value } \\
\hline & MFs* & NMFs & & & \\
\hline \multicolumn{6}{|l|}{ FP utilization } \\
\hline Yes & $114(56.7)$ & $87(43.3)$ & 201(65.9) & $1^{*}$ & \multirow[t]{2}{*}{$0.001 * *$} \\
\hline No & $32(30.8)$ & $72(69.2)$ & $104(34.10)$ & $2.94(1.79,4.87)$ & \\
\hline \multicolumn{6}{|l|}{ Contraceptive type $(\mathrm{N}=201)$} \\
\hline Injection & $92(56.1)$ & $72(43.9)$ & 164(81.6) & $1^{*}$ & \multirow{3}{*}{0.83} \\
\hline Pills & $15(60)$ & $10(40)$ & $25(12.4)$ & $0.88(0.72,1.5)$ & \\
\hline IUD & $7(58.3)$ & $5(41.7)$ & $12(6.0)$ & $0.91(0.82,1.63)$ & \\
\hline \multicolumn{6}{|l|}{ ANC use $(\mathrm{N}=304)^{* * *}$} \\
\hline Yes & $120(54.1)$ & $102(45.9)$ & $222(73)$ & $1^{*}$ & \multirow[t]{2}{*}{$0.001 * *$} \\
\hline No & $26(31.7)$ & $56(68.3)$ & $82(27)$ & $2.53(1.48,4.33)$ & \\
\hline \multicolumn{6}{|l|}{ ANC visits (N=222) } \\
\hline$<4$ times & $64(45.7)$ & $76(54 . .3)$ & $140(63.1)$ & $1^{*}$ & \multirow[t]{2}{*}{$0.001 * *$} \\
\hline$>=4$ times & $56(68.3)$ & $26(31.7)$ & $82(36.9)$ & $0.67(0.53,0.85)$ & \\
\hline \multicolumn{6}{|l|}{ Use of Institutional Delivery } \\
\hline No (home) & $109(46.8)$ & $124(53.2)$ & $233(76.4)$ & $1^{*}$ & \multirow[t]{2}{*}{0.29} \\
\hline Yes (health institution) & $37(51.4)$ & $35(48.6)$ & $72(23.6)$ & $0.83(0.49,1.41)$ & \\
\hline \multicolumn{6}{|l|}{ Utilization of PNC } \\
\hline Yes & $38(52.4)$ & $35(48.6)$ & $72(23)$ & $1^{*}$ & \multirow[t]{2}{*}{0.14} \\
\hline No & 109(46) & $127(54)$ & $235(77)$ & $1.39(0.82,2.39)$ & \\
\hline \multicolumn{6}{|l|}{ Use of child vaccination } \\
\hline Yes & 141(49.1) & $146(50.9)$ & 287(94.1) & $1^{*}$ & \multirow[t]{3}{*}{0.06} \\
\hline No & $5(27.8)$ & $13(72.2)$ & $18(5.9)$ & $2.51(0.87,7.22)$ & \\
\hline \multicolumn{5}{|l|}{ Vaccination status $(\mathrm{N}=287)$} & \\
\hline Complete & 73(47.4) & $81(52.6)$ & $154(50.5)$ & $1 *$ & \multirow{3}{*}{0.34} \\
\hline On track & $59(50.9)$ & $57(49.1)$ & $116(39.3)$ & $0.87(0.75-1.21)$ & \\
\hline Incomplete & $9(52.9)$ & $8(47.1)$ & $17(6.2)$ & $0.80(0.64-1.13)$ & \\
\hline
\end{tabular}

*Reference group, ${ }^{* *}$ statistically significant, ${ }^{* * *} 1$ missing, Abbreviations: HH: Household, OSZSF: Oromia special zone surrounding Finfine.

\subsection{Predictors of Mothers' Model Status: Were the Models Really Exhibited Differences}

Table 1-3 described variations in percentages over some of the socio-demographic characteristics, knowledge/awareness related to HEP\&MCH services, and utilization of $\mathrm{MCH}$ behaviors ( $\mathrm{pv}<0.05$ ). Religion, having 4-6 and 7-9 alive children, being oriented about the activities of HEWs, awareness for ANC packages, getting informed about delivery complication, awareness for PNC visit within 6 weeks after delivery, source of $\mathrm{MCH}$ information, FP utilization, ANC ever visit and ANC visit frequency were variables that initially produced variation in proportions between the MFs and NMFs. Utilization of delivery care, PNC and child immunization services, perceived benefit of institutional delivery, awareness about child immunization, age, and educational level were not demarcated between NMFs and MFs (see table 2). Accordingly, these variables were pulled into further adjustment analysis to identify the variables that strongly demarcated between NMFs and MFs. Table 4 displayed predictors for being $\mathrm{MCH}$ model. After adjustment; MFs were found to be different from NMFs based on number of alive children they had, orientation with HEW activities, utilization of FP, frequency of ANC visits, knowledge of ANC packages, awareness of PNC service, perceived informed level of pregnancy/delivery complication and media as source of $\mathrm{MCH}$ information. Details were put as follows:

In this study, the only socio-demographic characteristics that predicted mothers' model status were number of live children. NMFs were averagely $11 \%$ less likely [(AOR (95\% CI):0.89 (0.45-0.94)] to have higher (4-6) children compared MFs i.e. model families were more likely those mothers with higher (4-6) number of children: Neither fewer nor higher. The study found out that there were variations between NMF and MFs concerning knowledge/ awareness about HEP and $\mathrm{MCH}$ services. For example, mothers who were from NMFs were averagely about five folds more likely [(AOR $(95 \%$ CI): 4.83(1.99-11.69)] to report they were not well oriented about the activities/details of HEWs role as HEP implementers compared to mothers from MFs. However, the MFs and NMFs did not mention statistically significant different number of lists of HEWs' activities (refer table 2). NMFs were averagely about 1.5 times more likely [(AOR (95\% CI):1.56 (1.19-2.86)] to report media as their source of $\mathrm{MCH}$ information compared to MFs though generally major source of information for respondents was HEWs. Additionally, NMFs were averagely 74\% less likely [(AOR (95\% CI): $0.26(0.10-0.67)]$ to be informed by the HEWs about pregnancy/delivery complications compared to MFs. When, knowledge of ANC was checked, NMFs were averagely $18 \%$ less likely [(AOR $(95 \% \mathrm{CI}): 0.82(0.68,0.93)$ ] to know that ANC has extra packages (like immunization for safer motherhood and fetal health) apart from checkup of pregnancy status compared to MFs. Regarding awareness of PNC, NMFs were averagely nearly three folds more likely [(AOR $(95 \%$ CI): $2.75(1.41,6.75)]$ to report not aware of the need to visit for PNC within 6 weeks after delivery compared to mothers from MFs. Therefore, the above facts summarizes that NMFs seemingly had lesser attachment with HEWs, 
their activities and communication they were making than do the NMFs (Table 4). In fact, it was unknown whether model status facilitated the attachment or vice versa.

NMFs and MFs had also shown differences in $\mathrm{MCH}$ service utilization. To begin with family planning; NMFs were averagely four folds more likely [(AOR (95\% CI): 3.89 $(1.98,7.63)]$ not to use FP service at the time of the study.
Mothers from NMFs, at their earlier stage of continuum of $\mathrm{MCH}$ behaviors, i.e. early in pregnancy, were averagely two times more likely [(AOR $(95 \% \mathrm{CI}): 2.22(1.24-4.67)]$ to claim missing any visit for ANC compared to MFs. Furthermore, the NMFs were averagely $67 \%$ less likely [(AOR $(95 \% \mathrm{CI}): 0.33(0.17,0.64)]$ to report making at least four ANC visits compared mothers from MFs (Table 4).

Table 4. Predictors of being model for MCH behaviors, Sebeta Hawas district, OSZSF, December 2015 (N=305).

\begin{tabular}{|c|c|c|c|c|}
\hline \multirow{2}{*}{ Predictor variable } & \multicolumn{2}{|l|}{ Types of HH } & \multirow{2}{*}{ Crude OR (95\%CI) } & \multirow{2}{*}{$\begin{array}{l}\text { Adjusted OR } \\
(95 \% \mathrm{CI})\end{array}$} \\
\hline & MFs* No (\%) & NMFs No (\%) & & \\
\hline \multicolumn{5}{|l|}{ Religion $(\mathrm{N}=304)^{* *}$} \\
\hline Orthodox & $118(44.7)$ & $146(55.3)$ & 1 & 1 \\
\hline Muslim & $9(69.2)$ & $4(30.8)$ & $0.36(0.22,0.86)$ & $0.76(0.36,1.24)$ \\
\hline Protestant & $15(62.5)$ & $9(37.5)$ & $0.49(0.37,0.92)$ & $0.87(0.47,2.32)$ \\
\hline \multicolumn{5}{|l|}{ Know the role of HEWs } \\
\hline Yes & $137(55.9)$ & $108(44.1)$ & 1 & 1 \\
\hline \multicolumn{5}{|l|}{ FP utilization } \\
\hline Yes & $114(56.70$ & $87(43.3)$ & 1 & 1 \\
\hline No & $32(30.8)$ & $72(69.2)$ & $2.94(1.79,4.87)$ & $3.89(1.98,7.63)$ \\
\hline \multicolumn{5}{|l|}{$\mathrm{ANC}$ visit $(\mathrm{N}=304)^{* *}$} \\
\hline Yes & $120(54.1)$ & $102(45.9)$ & 1 & 1 \\
\hline No & $26(31.7)$ & $56(68.3)$ & $2.53(1.48,4.33)$ & $2.22(1.24,4.71)$ \\
\hline \multicolumn{5}{|c|}{ ANC visit frequency $(\mathrm{N}=222)$} \\
\hline$>=4$ & $56(68.3)$ & $26(31.7)$ & $0.67(0.53,0.85)$ & $0.33(0.17,0.64)$ \\
\hline \multicolumn{5}{|l|}{ Know ANC package } \\
\hline Checkup alone & $70(43.7)$ & $91(56.3)$ & 1 & 1 \\
\hline Checkup $^{+}$(immunization) & $76(54.7)$ & $63(45.3)$ & $0.64(0.40,0.87)$ & $0.82(0.68,0.93)$ \\
\hline \multicolumn{5}{|l|}{ Know PNC (within 6 weeks) } \\
\hline Yes & $21(75)$ & $7(25)$ & 1 & 1 \\
\hline No & $124(44.9)$ & $152(55.1)$ & $3.68(1.51,8.93)$ & $2.75(1.41,6.75)$ \\
\hline \multicolumn{5}{|c|}{ Source of MCH information $(\mathrm{N}=300)^{* * *}$} \\
\hline HEWs & $109(58.6)$ & $77(41.4)$ & 1 & 1 \\
\hline Other health professionals & $11(20.8)$ & $42(79.2)$ & $5.41(2.17,7.56)$ & $3.24(0.96,4.21)$ \\
\hline Neighbors \& relatives & $17(58.6)$ & $12(41.4)$ & $1.01(0.81,1.23)$ & $1.52(0.87,3.21)$ \\
\hline Media & $14(43.8)$ & $18(56.2)$ & $1.82(1.24,3.17)$ & $1.56(1.19,2.86)$ \\
\hline \multicolumn{5}{|c|}{ Informed about pregnancy or delivery complications $(\mathrm{N}=222)$} \\
\hline Yes & $28(78.4)$ & $8(21.6)$ & 1 & 1 \\
\hline No & $91(48.9)$ & $95(51.1)$ & $3.62(1.64,8.71)$ & $0.26(0.10,0.67)$ \\
\hline \multicolumn{5}{|l|}{ Number of live birth } \\
\hline $7-9$ & $14(48.3)$ & $15(51.7)$ & $0.81(0.76,1.12)$ & $0.94(0.54,2.72)$ \\
\hline \multicolumn{5}{|l|}{ Number of alive children } \\
\hline $1-3$ & $72(43.3)$ & $102(56.7)$ & 1 & 1 \\
\hline $4-6$ & $58(56.9)$ & $44(43.1)$ & $0.54(0.39,0.74)$ & $0.89(0.45,0.94)$ \\
\hline $7-9$ & $8(34.8)$ & $15(65.2)$ & $1.32(1.15,2.23)$ & $1.27(0.89,3.27)$ \\
\hline
\end{tabular}

*reference group, ${ }^{* *}$ catholic removed from analysis (zero cells), *** missing (5), Abbreviations: HH: Household, OSZSF: Oromia special zone surrounding Finfine.

In congruent to quantitative findings, the FGDs showed mothers from both groups were not using delivery, PNC and immunization services i.e. they were similar on those $\mathrm{MCH}$ outcome behaviors. In fact, the IDIs and FGDs expressed variation points between MFs and NMFs on each of later stages MCH behaviors: DC, PNC and immunization service utilization. Accordingly, we discuss each behavior as follows (refer to table 5 for details):

\subsubsection{Delivery Service Utilization}

Across to the FGDs women's none- use of delivery service was generally characterized by: First: no intention and plan to go for HF: perceived the TBAs were enough, health workers lack respectful and caring support during past deliveries at $\mathrm{HF}$, and perceived no need to deliver at $\mathrm{HF}$ unless complication was present). Second: no perceived vulnerability: perceived rare chance of experiencing complication. Third: inaccessibility of the service for those who intended to get it. However, the FGDs were also clearly conveyed the points of departure between the two groups. The first two features more or less characterized the NMFs and the third aspect mostly characterized the MFs. The nonmodel mothers were not yet perceived the relevance of delivering at HF. The model mothers lacked enabling 
environments (inaccessibility) to realize their intention. Therefore, the MFs and NMFs were slightly different on mechanisms through which they ended up not delivered at HF.

Less perceived relevance of $\mathrm{HF}$ for delivery (more common mentioned by NMFs) was facilitated by two main reasons. First, perceived adequacy of TBAs to manage deliveries: the TBAs were perceived as wise women, blessed handed, healer with just a touch, pain killer, child position and status assurer, long-lived experts with accumulated generational credentials, and more importantly still relied on especially by the non-model families. In fact, the model families were more likely to manifest a sort of modesty against the skills of TBAs, and tend to deny their use anymore. The second was perceived invulnerability to delivery complications: the use of HF seemed to happen only when delivery process gets complicated i.e. no anticipated complication- no institutional delivery. Closely linked with this idea and more importantly, most discussants perceived minimal chances of experiencing delivery complications (especially among NMFs). This idea was emanated from two relevant sources: past safe delivery experiences of their own (giving births without complications) and generational experiences (of getting safe assistance from local experts-the TBAs and storyline that their grandpas were giving births so safely). In fact, HF was believed to be more effective to manage complication than TBAs, even by the non-model families, if that happened at all. Accordingly, seemingly one of the good opportunities to deal with women for improved $\mathrm{MCH}$ behaviors was the non-objection of HF as a potential place for skilled birth attendances, because of perceived skill to manage complications by health workers.

On the other hand, the MFs were more critically challenged with past experience of disrespect by health workers during the past deliveries at HF, and inaccessibility. Perceived lack of concern and respect from health workers was adversely influencing $\mathrm{MCH}$ services. Experiences women faced during their or their relatives' past deliveries at $\mathrm{HF}$ affected their preference of places for successive deliveries. Health workers who were not caring, respectful and responsive pushed even the MFs away from delivering at HF. Women reported they needed support, caring and encouraging words and actions at the moment of their delivery, not disgrace. The experiences of disgust at HF led the women to foster their reliance on TBAs-who were perceived to be caring, encouraging and respectful. And, on top of this, inaccessibility claims for institutional delivery had a sort of hierarchical aspects that affected use of $\mathrm{MCH}$ services: lack of readiness for delivery, urgent nature of labor, no road departure to wait for vehicle (beyond the control), no transportation and no finance.

\subsubsection{The PNC and Child Immunization Service Utilization}

Both shared similar elements to display variations between the two groups, as they both happen after delivery. Across the FGDs with both groups: low level of awareness about PNC/immunization, post-partum social norms and closed health post occasions interacted with the services utilization. With regarding to awareness for the services; discussants from both groups confused immunization with PNC i.e. they perceived PNC visit was meant for child vaccination. And, PNC use was reported to happen after 45 days. In fact, this was commonly stated among women from NMFs. The postdelivery traditional practices were high likely to link with consecutive $\mathrm{MCH}$ services utilization: PNC and child immunization. Though both groups shared the practices and beliefs, the MFs claimed closed health occasions as reasons for not getting $\mathrm{MCH}$ services after delivery. Women approached believed to be powerful persons available in their locality, referred to as 'hammachiisaa'-literary means the one who takes newborns up in arms, who were supposed to bless their newborns. They also were supposed to stay at home for forty days after delivery-this was to prevent 'michii'-literary means allergy. The worst point was women might not have visited HF when they faced signs that sought medical consultation, like post-partum hemorrhage. Mostly, MFs claim that absence of the HEWs from their station: closure of HPs was a challenge to uptake of $\mathrm{MCH}$ services and products like child vaccines (including family planning), even after repeated visits..

Table 5. Shows matrix of qualitative findings, from across the FGDs and IDI, Sebeta Hawas, OSZSF, Ethiopia, December, 2015 (N=38 individuals across 4 FGDs and 4 IDIs).

\begin{tabular}{|c|c|c|}
\hline $\begin{array}{l}\text { Major themes: } \mathrm{MCH} \\
\text { contexts under which } \\
\text { modeling operates }\end{array}$ & Descriptions for the major themes (data based) & Supportive quotations (from the interviews) \\
\hline $\begin{array}{l}\text { 1. System challenges for } \\
\text { MCH Use }\end{array}$ & $\begin{array}{l}\text { System: comprised of poor follow up and supervision of HEP, } \\
\text { and work burden, additional unplanned assignment, turnover } \\
\text { and replacement of HEWs }\end{array}$ & $\begin{array}{l}\text { For example, District officials, the } \mathrm{MCH} \text { team leader said, } \\
\text { "to be a model family one has to attend three months } \\
\text { thorough training and have to put in to practices at least }\end{array}$ \\
\hline $\begin{array}{l}\text { 1.1. Follow up/ } \\
\text { supervision for HEWs } \\
\text { and models }\end{array}$ & $\begin{array}{l}\text { Follow-up challenge: Limited work on improving behaviors of } \\
\text { model families themselves and their level of influence. Slight } \\
\text { effort from district health office made to follow this issue } \\
\text { (only training). Registration and location of the number of } \\
\text { model families not well kept. Even tracking of MFs was not as } \\
\text { easy as mentioned by districts. Only few of the certified } \\
\text { models could be inconsistently noted so through observation. } \\
\text { Minimal follow support given to HEWs regarding her work on } \\
\text { and through models. }\end{array}$ & $\begin{array}{l}80 \% \text { of the total packages... in some cases people are forced } \\
\text { to fulfil what is expected from them without being convinced } \\
\text { and back slide latter." } \\
\text { HEW said, " ....compromised quality of the services, HEP } \\
\text { was rushing to increase number of model families and } \\
\text { offering training to be given for three months in a month } \\
\text { being certified for the sake of report only. The models might } \\
\text { have not further strengthened and followed till they exhibit } \\
\text { different behaviors" }\end{array}$ \\
\hline 1.2. High workload & $\begin{array}{l}\text { HEWs' work over burden: The HEWs served the entire HHs } \\
\text { in each ganda, both through outreach and in-the-health post. }\end{array}$ & $\begin{array}{l}\text { The HEWs said, “...the model families need follow up and } \\
\text { supervision from senior staff of the health center and from }\end{array}$ \\
\hline
\end{tabular}




\section{Major themes: $\mathrm{MCH}$ \\ contexts under which modeling operates}

1.3. Additional and too many unplanned tasks assigned

1.4. Turnover and replacement

2. Health care providers \& $\mathrm{MCH}$

2.1. Lack of concern and respect: health center workers

2.2. Absence of HEWs: Closed health posts

3. Mothers' view, experiences related to $\mathrm{MCH}$ utilization 3.1. Misconception on $\mathrm{MCH}$ :

3.1.1. No complicationno institutional delivery

3.1.2. PNC confused with child immunization

3.2. Perceived skills and respectful care from TBAs

\section{Descriptions for the major themes (data based)}

HHs were too many to be reached by 2 HEWs assigned for each village. The packages were also too many. During outreach the HEWs were not found in-the-health post. This challenged getting the services like child immunization, family planning etc.

Too many unplanned tasks imposed: HEP has been rendered by HEWs. And, the HEWs were found to elapse most of their times on meeting for unplanned activities at village and district levels. The meetings at times could last for a week or two, even extended. This competed over time with the routine tasks they were supposed to provide at health post. The meeting agendas could be farfetched at times from routine expected activities of HEP

HEWs turnover and replacement: Each health post was supposed to recruit 2 HEWs. But, HEWs were leaving their job claiming with burnouts and heavy work load vested on their shoulder with smaller number of them; there were then many health posts running by only one HEW and even some have none

Health care providers: health workers at HC and HEWs at HP Concern and respect: Experiences women faced during their or their relatives' past deliveries at HF determined their successive deliveries to happen at home, even seek the assistance from the TBAs. Health workers who were not caring, respectful and responsive pushed even the MFs away from delivering at HF. Women reported they needed support, caring and encouraging words and actions at the moment of their delivery, not disgrace. The experiences of disgust at HF led the women to foster their reliance on TBAs-who were perceived to be caring, encouraging and respectful.

Closed health posts: occasions for health posts was a challenge to uptake of $\mathrm{MCH}$ products like family planning and child vaccines. Sometimes, the health post remained close after repeated visits. In fact, the closure could be attributed to reasons ranging from system and strategy related (workload, outreach, too many meetings, etc) to HEWs' related (reluctance, lived in town and burnout).

Views \& experiences: Many of women's views on $\mathrm{MCH}$ challenges relate to delivery and post delivery services. This included: misconceptions on service packages, inaccessibility (urgent labor, distance, finance, too much beyond control) and post-delivery traditional practices.

No complication-no HF delivery: Many occasions exacerbated mothers' lack of delivery at HF: perceived to be skillful TBAs were present in their vicinity, urgent onset of labor, perceived invulnerability to complication (no or rare), they were located at a distant. Many women from NMFs perceived the surplus of HF pertaining to delivery was management of delivery complications, if any

PNC confused with child vaccine: Many discussants from both groups confused child vaccination on the $6^{\text {th }}$ week with PNC service. They were also mentioning that PNC was aimed to provide child vaccination service. This was commonly stated among women from NMFs.

TBAs perceived skill and respect: were perceived as wise women, blessed handed, healer with just a touch, pain killer, child position and status assurer, long-lived experts with accumulated generational credentials, and more importantly

\section{Supportive quotations (from the interviews)}

\section{the district."}

District health office head said, "... We need if we could get to more than $2 \mathrm{HEWs}$ for each village. They have too many jobs..."

The HEWs also said, "our expected jobs are not much compared with our number. We are supposed to stay in clinic and conduct out-reaches too. The packages are too many"

For example, The HEW supervisor said, “....most of HEWS were not found at the health post though they were supposed to be as per the HEP guideline. They spent half of the working time on travel which was aggravated by unplanned emergency assignments vested on them from the districts including frequent meetings."

HEW supervisor said, “...the main reason for HEWs leaving their job was burnout and heavy tasks, too many works. The problem was no or delayed replacement when they left."

For example, one FGD discussant woman of age 28 from MFs said, “...My elder sister was in labor. We took her to the health center and the nurse appeared after long waiting. During examination she was speaking impolitely..." Another discussant from MFs said, "....But there is a lot of care from TBAs and you get a lot of encouraging words when you give birth at home among your family members who respect and care for you...."

One mother from MF said, "my neighbor told me that she visited health post two times for family planning and missed them from office and obliged to go to Sebeta town. Now I decided to use private clinics and Sebeta health center." Another mother of age 37 from NMF said "My child is about three months and a week now and not yet vaccinated. I took my child to health post and didn't get HEWs there. Latter my friends informed me that she have had meetings at district. Latter after a month they came my-home while I was away from home with my baby for work and missed each other. She toldmy neighbor to be back after a week. Again when I was back I visited them and didn't appear for another a month and they seem very busy. They also live in towns to just in the village"

For example, one FGD discussant woman from NMFs said, "There is no transportation to go to health institution once the labor set on, and we don 't worry for we do have the TBAs unless complication occurs."

Another mother of age 31 from NMFs said, "it is good to deliver at health institution and I have no objection for that, but I didn't encounter any problem when I delivered five of my children at home, because I saint Mary made my labor easier." Another mother from MFs said, "...I have attended antenatal care services both from HEWs and nurses. I was told during ANC to deliver at health institution; but no complication and difficulty during my labor and I delivered soon by the support of TBAs at my home." 


\begin{tabular}{ll}
\hline $\begin{array}{l}\text { Major themes: MCH } \\
\text { contexts under which } \\
\text { modeling operates }\end{array}$ & Descriptions for the major themes (data based) \\
\hline & $\begin{array}{l}\text { still relied on especially by the non-model families. In fact, the } \\
\text { model families were more likely to manifest a sort of modesty } \\
\text { against the skills of TBAs, and tend to deny their use anymore. } \\
\text { They were also claimed as respectful }\end{array}$ \\
& $\begin{array}{l}\text { Multiple hierarchical inaccessibility aspects: (commonly } \\
\text { stated by MFs }\end{array}$ \\
$\begin{array}{l}\text { 3.3. Inaccessibility } \\
\text { (delivery services) }\end{array}$ & $\begin{array}{l}\text { Inaccessibility (urgent labor and lack of readiness): Though it } \\
\text { is a natural phenomenon for labor to happen unexpectedly, }\end{array}$ \\
$\begin{array}{l}\text { Urgent labor and } \\
\text { readiness }\end{array}$ & $\begin{array}{l}\text { lack of psychological or financial readiness for it was a } \\
\text { challenging aspect. For some woman home delivery happened } \\
\text { 3.3.1. No road to join } \\
\text { vehicle }\end{array}$ \\
3.3 .2$. No transport-road
\end{tabular}

3.3.2. No transport-road access

3.3.3. No finance-take vehicle

3.4. Traditional practices 3.4.1. "Hammachiisaa": as post-partum competitor for PNC and child immunization

3.4.2. Local massage by TBAs and timing of labor, not just because of lack of psychological readiness. They might have used every required package till the moment of labor and decided to deliver at HF. But, the labor could come in mid-night- The time they perceive being out of support and they did not access anything at ease. Inaccessible-just beyond control (road access): Many mothers especially from MFs claimed that they have no problem of evidence. They reported that they received awareness creation trainings about ANC, immunizations, institutional delivery, etc. And, delivering at HF happens just because it was beyond their control to manage visiting $\mathrm{HF}$ as of distance, not knowledge or reluctance:

Inaccessible-transportation: Next to access to road, access to transport will be the next challenge that could delay, especially when the time labor was inconvenient. Some women perceive the benefit of institutional delivery and even prefer to get their delivery attended there. But, they may simply lack transport. Inaccessible-finance: Lack of financial readiness was a critical challenge women were mentioning specially from MFs. It especially worsens home delivery occasions when it added urgency of labor. Here road accessed and transport was potentially available but still no many to pay for. The accustomed practices: included ranges of traditional practices both before and following delivery event those were high likely to link with consecutive $\mathrm{MCH}$ services utilization: PNC and child immunization. Women approached spiritually believed to be powerful persons available in their locality, referred to as 'hammachisaa'-literary means the one who takes up in arms, who were supposed to take the new-born in arms and give blessing. They also were supposed to stay at home for forty days after delivery-this was to prevent 'michii'literary means allergy, not even go for child vaccination. The worst was women might not have visited HF when they faced signs that sought medical consultation, like post-partum haemorrhage.
Supportive quotations (from the interviews)
For example, one woman from NMFs stated, “....after delivery, we were supposed to go to health posts to immunize our new-born, we had to go till 45 days. We don't need to go for ourselves. We were finished, now we gave birth...."

For example,

One woman of age 25 from NMF group said "we do have TBAs and I, all my relatives and the villagers gave birth on her hand; she has a blessed hand and no need of going to health institution unless complication occur."

Another woman from NMF said, “...I confirmed that those traditional healers are so wise and know all the position of the baby. Their hands were curing whenever they touch. For example, one woman from MFs said, "I was not ready when my labor set on...I also did not have cash on my hand .... finally I delivered at home."

Another woman of 23 from MFs reported, "I attended ANC services four times at Sebeta Health center and very pleased for the care I got from the nurses. I was told not to give birth at home in order to avoid too much bleeding during delivery so that I and my baby will be kept safe. But unfortunately my labor was at night time, it was hard time for both of us and this way I delivered at home."

For example, one woman of age 21 from MFs explained, “...We were well trained by HEWs one by one on vaccination, antenatal care and institutional delivery... But I gave birth my two children at home because my house is very far from the road departure and there was difficulty to travel being on labor up to the point of road."

For example; one FGD discussant woman of age 27 from MFs said, "As my sister over there

said, I know the benefit of institutional delivery and I prefer to give birth there. I gave birth to my middle child in health center where I attended my antenatal care but I didn't get transportation for the first and last child whom I gave birth at home."

For example; one mother from MFs reported, "I was not ready when my labor set on and I did not have cash on hand. The labor did not give me time to search money for credit. This was how I gave birth at home... and my life was endangered due to too much bleeding and I was not conscious when I was taken to health center after a week." For example, one mother from NMF said, "....after delivery, we had a trend of going for 'hammachisaa'....he blesses the baby to grow well after taking the baby and holding it on his 


\begin{tabular}{lll}
\hline $\begin{array}{l}\text { Major themes: } \text { MCH } \\
\text { contexts under which } \\
\text { modeling operates }\end{array}$ & Descriptions for the major themes (data based) & Supportive quotations (from the interviews) \\
\hline & $\begin{array}{l}\text { arms. This is believed to keep the baby healthier and grow } \\
\text { productive as an adult" Another woman from NMFs said, } \\
\text { "....we did not go out. When we give birth at home, we } \\
\text { receive an advice. We were restricted to go out until forty } \\
\text { days for fear of spirit strike locally called "michii". Even } \\
\text { they might not come out, when they fill ill signs." }\end{array}$ \\
$\begin{array}{l}\text { For example, one mother of age } 29 \text { from NMFs said, "It is } \\
\text { usual thing to attend abdominal massage service given by } \\
\text { Traditional healers in order to avoid abdominal cramp } \\
\text { during pregnancy. I had used for two of my pregnancies and } \\
\text { Igot relief soon after the services." }\end{array}$ \\
\hline
\end{tabular}

Abbreviations: FGDs: Focus Group Discussion, IDI: In-depth Interview, OSZSF: Oromia Special Zone Surrounding Finfine.

\section{Discussion}

One of the approaches of HEP was training of model families who were expected to help diffuse health messages leading to the adoption of the desired practices and behaviors by the community, mothers of reproductive age groups. The production of the model families starts with training and through close support and follow-up it achieves the goal of modeling $\mathrm{MCH}$ behaviors: FP, ANC, DC, PNC and child immunization. This study produced evidences about model and non-model families targeting to $\mathrm{MCH}$ utilization behaviors and that can inform achievement of the HEP strategies. In order to easily demonstrate variations between the two groups, we categorized $\mathrm{FP} / \mathrm{ANC}$ use as early stage utilization behaviors and the $\mathrm{DC} / \mathrm{PNC} / \mathrm{Child}$ immunization as later stage utilization behaviors on the continuum of $\mathrm{MCH}$ service utilization behaviors. This category was intended because this study found out that models had exhibited explicitly differently on behaviors that happen before or early in pregnancy and while they didn't on behaviors that were late in pregnancy or post. Major findings were discussed with closely related evidences, guidelines and behavior change theories to search for implications.

Accordingly, we first introduced major findings as follows. This study generally observed differences between MFs and NMFs against respondents' background, knowledge or awareness of $\mathrm{HEP} / \mathrm{HEW}$ ' role/MCH services and $\mathrm{MCH}$ utilization practices. The observed variations between MFs and NMFs were captured through both quantitative and qualitative findings. In fact, there were similarities between the two groups against some $\mathrm{MCH}$ relevant knowledge and practices. Number of live children the mothers had was the only background characteristics that demarcated the groups. The major demarcation between the two groups in terms of $\mathrm{MCH}$ practices was family planning and antenatal care utilization. Though qualitative aspects of the study observed variations in commitments to engage on the later $\mathrm{MCH}$ behaviors, practically no statistically significant differences were observed on DC, PNC and immunization between the groups. The study found out that the model families were more informed about role of HEW as HEP worker, ANC, pregnancy-delivery complications and $\mathrm{PNC}$ compared to non-models. The HEWs were significantly mentioned to be source of $\mathrm{MCH}$ information for model mothers compared to other sources; other health professionals and media which in turn were commonly mentioned by the non-models.

Variations with the level of awareness/ information about $\mathrm{HEP} / \mathrm{HEW}$ and $\mathrm{MCH}$ services between model and nonmodel groups could be attributed to particular training the models received about the HEP packages and strategies. The HEP working guide advises training to be given to model families [6]. As the qualitative findings also showed the model families had supposed to be trained for 3 months before they were graduated as models (refer to table 5). One relevant question, for this particular area of study, was about the characteristics of cohort of mothers who were models compared to non-model ones, and how they were selected to involve as trainees for being models? According to this study, no other socio-demographic characteristics significantly split up the mothers into model and non-model groups except the number of live children they had. Those mothers who had 46 live children were more of models compared to mothers that had $<4$ or $>6$ children. Perhaps, it seemed models were first selected for training based on their family size on one hand. And, on the other hand, the selection of women for initial investment as models so that they reach other mothers was not purposive. According to diffusion of innovation (DOI) theory (one of the most effective behavior change theories), new behaviors (in this case, $\mathrm{MCH}$ utilization) best diffuse quickly when program implementers work through purposively selected individuals, groups or other unit of adoption who potentially acts as advocates. In fact, these advocates are supposed to be well equipped, knowledgeable and adopt the behaviors themselves first before they reached others. Then, after significant proportion of these early adopters (advocates) were targeted by the program objectives, the behaviors will soon diffuse on its own through locally existing communication forms including interpersonal discussions [32]. Though variations in the level of knowledge most probably linked to the training the model families, both groups were not different in knowledge of family planning and child immunization awareness. This could be because of high magnitude of ever hearing about those services that could hide differences: only $9(3 \%)$ of mothers were unable to mention any FP method and $2(0.66 \%)$ of them mentioned 
never aware of child immunization..

In this study, though mothers from model families and non-model families had shown differences on early stage $\mathrm{MCH}$ utilization behaviors, they did not on later $\mathrm{MCH}$ utilization behaviors. This means utilization of FP and ANC services were significantly better attached to mothers from model family than non-model ones while utilization of DC, PNC and child vaccination were not significantly explicitly attached to being model. The variations on early stage $\mathrm{MCH}$ utilization behaviors between the two groups were perhaps because of two things: the trainings the model families received and the utilization of these services did not require too much resource: time, money, and access to the service outlet points-health posts unlike services in late pregnancy period-delivery or post. Mothers from model families converted their knowledge into commitments and actual utilizations of FP and ANC services compared to the nonmodels. Therefore, they can help diffuse the utilization of those services. Similarities of both groups on later stage $\mathrm{MCH}$ utilization behaviors could be because these services required too much resource to access the services: time, money, vehicles infrastructures needed for delivery services including facility and roads. In fact, similarities on PNC and immunization services may be attributed to competing traditional practices like forbidden going out after giving births and closure of health posts as of workload, unplanned tasks and meetings the HEWs attended. Many studies conducted on $\mathrm{MCH}$ services utilization behaviors (FP, ANC, DC, immunization services utilization) documented that knowledge, commitments/intention; traditional beliefs and accessibility of services determine use of $\mathrm{MCH}$ services [1724]. Another study identified limited number of HEWs, often closed health posts were critical challenges to $\mathrm{MCH}$ service utilization [25]. Basically FP and ANC can be utilized at health post level i.e. at ganda closer to where the mothers live while skilled institutional delivery services were rendered at health center level i.e. located at more distant settings away from where rural mothers live. The HSDP I-IV and HEP guidelines clearly specified that health posts and HEWs were not well equipped and skilled for rendering skilled birth attendance services. Mothers were expected to travel to health centers where the skilled/institutional delivery services were rendered [3-6, 36-37]. Qualitative findings clearly put hierarchical inaccessibility aspects that hidden possible demarcations between the two groups though model families seemed be better committed to use the services. Plus to that there were challenging multi-level contexts through which $\mathrm{MCH}$ service were delivered and within which frame the model families were expected to carry out their modeling tasks (refer to table 5). Therefore, health system contexts handicapped mothers from modeling especially the later stage $\mathrm{MCH}$ utilization behaviors. Model families were challenged with contexts beyond their control.

The findings carried relevant messages for HEP designers and implementers that deemed further discussion over its implications for improvement of $\mathrm{MCH}$ practices among mothers. The study portrayed that women from model families were having practices that can be observed and adopted by other women around at times before or early in pregnancy. They can be used for enhancing FP and ANC utilization. According to DOI theory, Social cognitive theory (SCT) and other behavioral theories, models (in this case, model families) were intended to exhibit healthier roles, practices, experiences that we needed others to give attention to, observe, adopt and later become advocate themselves. In this case, we purposely were supposed to invest resources over these models in a way we like others will most probably follow either because the target behavior has overtly conveyed benefits to the target audiences or become a new social norms to comply with [32, 34-35]. Nonetheless, system challenges were significantly responsible for similarities between the two groups though variations were expected. The above theories (DOI and SCT) clearly specified complexity of the systems and incompatibility of service delivery outlets and mechanisms can pose critical hindrances to adoption of service $(\mathrm{MCH})$ utilization and its further diffusion among members of target population in a given community [32, 34-36]. Finally, this study was not without limitations. Firstly, findings in this study were not thoroughly compared with other studies because of limited access to similar literatures. Up to our knowledge there were deficit of comparative studies that focused on variations in health service use based on model status and similar contexts. Therefore, we used general evidences that did not compare both groups. Secondly, the scope of this study was limited to look at $\mathrm{MCH}$ service utilization demarcation points between model and non-model families. It was not aimed to determine factors that influenced specific $\mathrm{MCH}$ behaviors separately for both groups. Thirdly, this study was limited to one district of OSZSF, though it included many villages. Regarding potential sources of bias, this study could have exposed to social desirability bias; may hide variations through misclassification as any mother needs to be positively evaluated against $\mathrm{MCH}$ services utilization.

\section{Conclusion}

Modeling $\mathrm{MCH}$ behaviors within the context of HEP delivery for rural community was in its infantile stage. Mothers from model families had practices that can be observed by other women in their surroundings. Family planning and repeated antenatal care service utilization were some of the areas where HEP can be effective in using them as advocates to prevent or care for pregnancy in its early stage. Nonetheless, model mothers did not exhibit practices that can set examples for others to observe regarding utilization of $\mathrm{MCH}$ services in late pregnancy- to the point of institutional delivery including post-natal care and child immunization. Model mothers did not keep on acting their model role across all relevant stages on the continuum of maternity: before, early and late in pregnancy. There were contexts beyond the control of the mothers leaving hindrances for exhibiting model 
practices for late stage $\mathrm{MCH}$ behaviors. $\mathrm{MCH}$ service delivery system had bottleneck features that disabled conversion of commitments and intentions model mothers had in order to use delivery, PNC and immunization services. Hierarchical inaccessibility aspects: services outlets, distance, transport and finance were critical challenges for modelling specifically delivery service utilization. Closure of health posts at work time because of factors related health system and health extension workers were challenges especially for post-natal care and child immunization utilizations. Thereof, we claim the findings of this study as urgent given that $\mathrm{MCH}$ behaviors, particularly skilled birth attendances, has been identified by different stakeholders as relevant strategy to reduce maternal and child mortality rates. Therefore, this study calls for earnest work to improve late stage maternity service utilization behaviors in general and facilitating modeling strategies that can enhance the services utilization in particular. Furthermore, the HEP designers and implementers should work to aiming to produce model mothers distinctly for delivery care, postnatal care and child immunization services and provide them reinforcing names.

\section{List of Abbreviations}

ANC: Antenatal Care, AOR: Adjusted Odds Ratio, COR: Crude Odds Ratio, DC: Delivery Care, EDHS: Ethiopia Demographic Health Survey, FP: Family Planning, HEP: Health Extension Program, HEWs: Health Extension Workers, HC: Health Center, HP: Health Post, PNC: Postnatal Care, MCH: Maternal and Child Health, MFs: Model Families, NMFs: Non-model Families, OR: Odds Ratio, OSZSF: Oromia Special Zone Surrounding Finfine, PHCU: Primary Health Care Unit

\section{Declarations}

Ethics approval and consent to participate: Jimma Univeristy Public health and medical sciences ethical comittee.

\section{Consent for Publication}

Not applicable.

\section{Availability of Data and Material}

The datasets used analyzed during the current study are available from the corresponding author on reasonable request.

\section{Competing Interest}

The authors declare they have no competing interest.

\section{Funding}

Jimma University financially supported this study. Jimma
University funds researches for academic purposes.

\section{Authors' Contributions}

YKL and GER conceived the idea. GER, YKL, EG designed the study. YKL drafted the manuscript. EG and GER participated in the critical review of the manuscript. All authors gave their final approval of the version of the manuscript submitted for publication.

\section{Acknowledgements}

The authors acknowledge Sebeta Hawas district health office for facilitating this study. Our gratitude also goes to participants who were involved in this study. At last but not the least we are thankful for data collectors.

\section{References}

[1] John J Hall and Richard Taylor: Health for all beyond 2000: the demise of the Alma-Ata Declaration and primary health care in developing countries, Med J August 2003; 178 (1): 1720

[2] Ministry of Health: 1986. Comprehensive Health Service Directory. Addis Ababa.

[3] Ministry of Health. 1985. Primary Health Care Review. Addis Ababa.

[4] Federal Democratic Republic of Ethiopia Ministry of Health. Health Sector Development Program IV 2010/11 - 2014/15 October 2010.

[5] Health Extension and Education Center. Federal Ministry of Health Addis Ababa, Ethiopia June 2007.

[6] Federal Ministry of Health of Ethiopia: Health extension program in Ethiopia. Addis Ababa: Health Education Center, 2007.

[7] World Health Organization. 2005. World Health Report 2005: Make Every Mother and Child Count. World Health Organization, Geneva.

[8] Improved access to maternal health services. WHO 98.7. Geneva: WHO. World Health Organization (WHO). 1998.

[9] Better health in Africa: Experience and lessons learned. Washington, D. C.: World Bank. World Bank. 1994a.

[10] Countdown to 2015 decade report (2000-10): taking stock of maternal, newborn, and child survival.

[11] The United Nations Children's Fund (UNICEF). Ethiopia Statistics. Basic Indicators 2012:Re-trievedon February 17,2012:http://www.unicef.org/infobycountry/ethiopia_statisti cs.html.

[12] The Millennium Development Goals Report 2012. United Nations; New York, 2012.

[13] Ethiopia Demographic and Health Survey 2005. Central Statistical Agency Addis Ababa, Ethiopia ORC Macro Calverton, Maryland, USA September 2006. 
[14] Ethiopia Demographic and Health Survey 2011. Central Statistical Agency Addis Ababa, Ethiopia ICF International Calverton, Maryland, USA March 2012.

[15] Central Statistical Agency [Ethiopia] and ICF International. 2012. Ethiopia Demographic and Health Survey 2011. Addis Ababa, Ethiopia and Calverton, Maryland, USA: Central Statistical Agency and ICF International.

[16] Ahmed A: Maternal Mortality Trend in Ethiopia. Ethiop J Health Dev. 2010, 24 (1): 117-120.

[17] Yalem Tsegay Assfaw, Determinants of Antenatal Care, Institutional Delivery and Skilled Birth Attendant Utilization in Samre Saharti District, Tigray, Ethiopia.

[18] Negalign B., Yohannes H/M., Utilization of clean and safe delivery service package of health services extension program and associated factors in rural gandas of Kafa zone, southwest Ethiopia.

[19] Zelalem B., Gashaw A., Tadesse A., Gizachew A., and Digsu N. Determinants of skilled attendance for delivery in Northwest Ethiopia: a community based nested case control study: 2013.

[20] Alemayehu Sh., Fekadu M., and Solomon M.: Institutional delivery service utilization and associated factors among mothers who gave birth in the last 12 months in Sekela District, North West of Ethiopia: A community - based cross sectional study.

[21] Yared M. and Asnaketch M., Utilization of Maternal Health Care Services in Ethiopia, Ethiopian Health and Nutrition Research Institute Addis Ababa, Ethiopia ORC Macro Calverton, Maryland, USA. November 2002.

[22] Gurmesa T. etal:Antenatal care service utilization and associated factors in Metekel zone, Northwest Ethiopia Benishangul Gumuz Region, North West Ethiopia: JanuaryFebruary 2007.

[23] Alemayehu Sh., Fekadu M. and Solomon M. Institutional delivery service utilization and associated factors among mothers who gave birth in the last 12 months in Sekela District, North West of Ethiopia: A community - based cross sectional study: August, 2010.

[24] Addis Alem F. and Meaza D. Prevalence of institutional delivery and associated factors in Dodota Woreda (district), Oromia regional state: December 2012.

[25] Zewdie B., Ameyu G, Yohannes K., Mulusew G. Mothers' experiences and satisfactions with health extension program in Jimma zone, Ethiopia: a cross sectional study: BMC Health Services Research 2013, 13: 74.

[26] Integrated Community-based Maternal, Newborn and child health and Nutrition Intervention Dakar 2011.

[27] Rose NM, Japhet Z K, Melkzedeck T., Leshabari, Siriel NM. Albrecht J, Declare M.: Use pattern of maternal health services and determinants of skilled care during delivery in Southern Tanzania: implications for achievement of MDG-5 targets: December 2007.

[28] Leslie, J., and G. R. Gupta. Utilization of formal services for maternal nutrition and health care. Washington, D. C.: International Center for Research on Women. 1989.

[29] Determinants of use of maternal-child health services in rural Ghana. Journal of Biosocial Science 32 (1): 1-15. Addai, I. 2000 .

[30] African Journal of Reproductive Health 2 (1): 73-80. Addai I. 1998. Demographic and sociocultural factors influencing use of maternal health services in Ghana.

[31] Response of parents to five killer diseases among children in a Yoruba community, Nigeria. Social Science \& Medicine 32 (12): 1379-1387. Adetunji, J. A. 1991.

[32] Rogers, E. M. Diffusion of Innovations. (5th ed.) New York: Free Press, 2003.

[33] 2007 Population and Housing Census of Ethiopia: Results for Oromia Region, Volume 1 (accessed 13 January 2012).

[34] Karen Glanz, Barbara K. Rimer, K. Viswanath, editors. Health Behavior and Health Education: Theory, Research and Practice. $4^{\text {th }}$ edition. Chapter 8. Pages $169-185$. $4^{\text {th }}$ edition. Jossy-Bass a Wiley Imprint. www.jossybass.com.

[35] Yitayal M, Berhane Y, Worku A, Kebede Y. The community based Health-extension program significantly improved contraception utilization in West Gojjam Zone, Ethiopia, Journal of Multidisciplinary Health care, 2014: 7 pages 201208. https: //doi.org/10.2147/JMDH.s62294.

[36] Fisseha G., Yemane B., Alemayehu W., Wondessen T. Distance from Health Facility and Mothers perception of quality related to skilled delivery service utilization in northern Ethiopia. International Journal of Women's Health. 2017: 9 749-756.

[37] WHO. Service availability and readiness assessment 2016. Summary report. Ministry of Health $(\mathrm{MOH})$ Ethiopia. 